This PDF is a selection from an out-of-print volume from the National Bureau of Economic Research

Volume Title: The State of Monetary Economics

Volume Author/Editor: Universities-National Bureau Committee for Economic Research

Volume Publisher: NBER

Volume ISBN: 0-87014-307-7

Volume URL: http://www.nber.org/books/univ65-1

Publication Date: 1965

Chapter Title: Short-Run Objectives of Monetary Policy

Chapter Author: Guy Noyes

Chapter URL: http://www.nber.org/chapters/c5185

Chapter pages in book: (p. 147 - 155) 


\title{
SHORT-RUN OBJECTIVES OF MONETARY POLICY
}

\author{
Guy E. Noyes, Board of Governors, Federal Reserve System
}

$\mathrm{O}^{\mathrm{B}}$ F what I have seen of the work of the Commission on Money and Credit, one thing stands out. It is a part of one question addressed by one task force to the Federal Reserve Board, and it reads as follows: "Given the customary credit control instruments and the ultimate objectives of price stability, highlevel employment, and economic growth how is monetary policy formulated in the short run? For instance, what sort of factors are weighed in determining current policy, what guides are utilized and what are the immediate objectives of policy?"

The merits of the Board's reply, the many contributed papers, the Commission's Report, and recent monetary policy itself, are all certainly debatable - but I submit, if you will pardon the use of strong language, that this is a damned good question. It asks, politely but firmly, that we omit the usual garbage about opposition to sin and advocacy of motherhood, and just say what it is we are trying to increase, decrease, or hold still.

The Board's reply ran to some 35 doublespaced pages. The burden of drafting was carried by my colleague, Woody Thomas, who was assisted and hindered at various stages by other members of the staff. I would argue that it is a good reply, by any standards, and an outstanding one, after allowance is made for the necessity of producing it in an institutional framework. It is necessarily complicated by the inescapable fact that, even in the short run, the monetary authority is confronted with a variety of measures by which it may judge the impact of its operations.

Any single short-run objective has obvious deficiencies. The trouble with the bill rate as an exclusive short-run target is, I think, widely understood. The situation with respect to the use of a free reserve target is somewhat different. This synthetic pearl of a number has many virtues. It is simple, easy to understand, largely devoid of seasonality, closely related to many significant factors affecting policy, and it is published for all the world to see every Thursday. It also has certain deficiencies. So far as I have been able to ascertain, everyone is convinced that he himself understands these clearly, but has grave doubt that anyone else does.

I am going to take a giant step and assume that this audience understands both the virtues and vices of free reserves and plunge ahead on that basis.

A part of the reply to the question I mentioned at the outset ran as follows:

Whatever broad influences may flow from their actions, the Board of Governors and the Federal Open Market Committee are fully aware that the particular economic or financial variable over which they have anything approaching full and direct control is the total of commercial bank reserves. Through this control, they exert a strong influence directly on total loans and investments and total deposits of banks and indirectly some influence on spending, investment, and saving by the public in general. But, at any given moment, the choice for Federal Reserve policy lies between various degrees of restraint upon or encouragement to expansion of bank credit through altered reserve availability.

I believe there has never been much question that the volume of reserves available to the banking system is at least one of the appropriate short-run objectives of policy. The problem has been to bring it under control statistically, and it is with respect to our efforts to tame this beast that I shall address the remainder of these brief comments.

One of the great problems in measuring significant changes in reserve availability in the short-run has always been the substantial recurrent and random variation. If we are to use effectively targets expressed in terms of net additions to (or decreases in) the reserve base, we must be able to distinguish between changes that are purely seasonal or otherwise transitory and those of a more fundamental nature. It is not too difficult to see these trends in the longer run - from year to year or even from quarter to quarter - but it is almost impossible to spot them in the raw data in the shortrun.

As you all know, far and away the bulk of the reserve provision and absorption in any 
year is to offset seasonal swings. Therefore, a measure based on total reserves must first be adjusted to make allowance for purely seasonal operations. In this case, somewhat more than the usual amount of statistical legerdemain was required, since for short-run purposes it is necessary to have weekly seasonal factors.

A second kind of adjustment built into the available reserves measure pertains to changes in federal government deposits at commercial banks. These balances, chiefly Treasury tax and loan accounts, go through wide gyrations whenever tax, expenditure, and financing flows fail to mesh precisely. These changes in Treasury balances have little independent economic significance; banks generally realize that large swings are transitory, and certainly they have no effect upon Federal spending programs. It can be argued, therefore, that reserves provided or absorbed by changes in Treasury accounts should be excluded for much the same reason that we calculate reserve availability net of many other factors that provide or absorb reserves. To make our reserve measure correspond with this judgment, we subtract from the total whatever amounts of reserves are required behind government deposits. This is not to say that the occasional shifts from private to public deposits, and back, do not have a significance with respect to the privately owned money supply; those shifts that are seasonally repetitive are allowed for by our program for seasonally adjusting available reserves, while more irregular shifts that might be associated with private purchases of a new Treasury issue are allowed to appear as a decline in the available reserves measure.

Through these adjustments we arrive at the net of what we call "available reserves" the net change in total reserves after allowing for reserves provided or absorbed to offset seasonal factors and changes in Treasury tax and loan balances at member banks. For the period since mid-196r, this is shown by the top line on Chart I. It portrays from week to week the increase (or decrease), seasonally adjusted, in the reserves available to support private deposits at member banks. One school of purists, but not another, prefer to also deduct borrowings, thus arriving at a nonborrowed available reserve concept; in other words, the net increase (or decrease) in reserves, resulting from operations at the System's initiative.

As I am sure you have already deduced, the distance between the nonborrowed line and the bottom line-required reserves against private deposits, seasonally adjusted - is your old friend free reserves.

For better or worse, the change in available reserves is one of the short-run objectives of policy presently being employed by the Federal Open Market Committee. For example, these are the numbers behind the expressed objective, contained in that part of the last published policy directive (December r9, r96r), which said that ". . . operations for the System Open Market Account shall be conducted with a view to providing reserves for bank credit and monetary expansion (with allowance for the wide seasonal movements customary at this time of the year), but with a somewhat slower rate of increase in total reserves than during recent months."

I am not sure whether or not an available reserve target formulated in these terms is a good short-run objective for the monetary authority, but the concept should be a gold mine for its critics. Why did the monetary authorities cause - or allow - available reserves to increase at an annual rate of about 8 per cent from the first part of August to the last part of December I96r? Wouldn't 6 or 5 or 4 , or something else, have been more appropriate? Or, better still, granting that the up and down in December and January can be attributed to an extraordinary seasonal bulge, why did they bring the growth rate to a grinding halt in February and March of this year? As you can see, it has endless possibilities.

Without further ado, I present you herewith, free of charge, the handy academicians' prefabricated do-it-yourself FRB baiting kit. Have fun! 
Chart I. - Reserves Supporting Private Deposit, Seasonally Adjusted, May 3 to April it, ig62

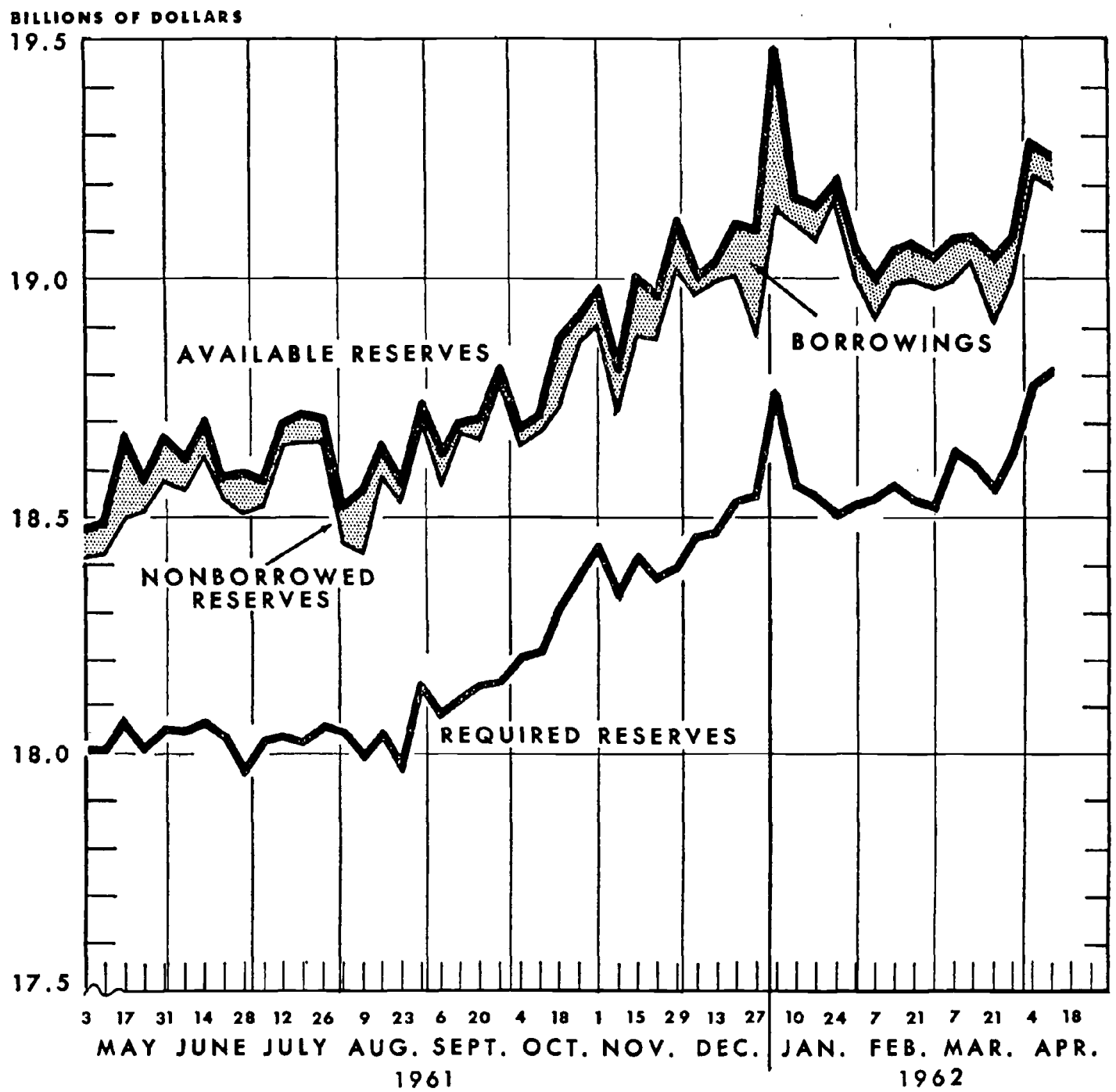

NoTE: Adjusted required reserves equals seasonally adjusted required reserves beld against actual demand deposits adjusted - not interbank demand deposits - and time deposits. Adjusted available reserves equals adjusted required reserves plus actual excess reserves. Adjusted nonborrowed reserves equals available reserves less actual member bank borrowings. Annual rates of monetary expansion based on seasonally adjusted levels of reserves, held against demand deposits adjusted and time deposits in November rg6r.

\section{COMMENT}

Herbert Stein,

Committee for Economic Development

I am pleased that others have risen to explain and defend the Commission on Money and Credit in response to some of the condescending and scornful remarks that have been made about it. I would like to add a few comments of my own on this subject.

Certainly there are problems within its field that the Commission did not solve. These un- solved problems may be the most important ones. It is the function of economists to point this out and to try to fill the gaps. But we should also try to be clear about the reasons for the deficiencies. We should not kid ourselves with the idea that the deficiencies exist because the Commission consisted of twenty men who were not economists and who had various interests not usually shared by economists in short, because they did not listen to us. 
I believe the Commission report fairly reflects the current state of professional economic thinking in the field it covers. I think the Commission's findings not only are consistent with the professional consensus but also pretty well exhaust that consensus. You will understand that I have taken no survey and report only fragmentary observation. But I am willing to accept your judgment on the matter. If you ask yourself not what you think but what your professional colleagues, somehow taken as a whole, think - would the results be so much different from the Commission's results?

Of course, even if I am correct this does not absolve the Commission. The Commission did not have to buy the professional consensus. Certainly we could hope that the Commission would do much better than the consensus. But if the Commission is not absolved, we as economists must also share responsibility. Those who participate in the expert consensus are hardly in a position to complain; those who do not should first ask themselves why they have failed to convince their colleagues.

In his paper, Martin Bronfenbrenner listed three circumstances that might, in his words, "disturb the apologetic smugness of practical men regarding our monetary and fiscal arrangements, and permit reform proposals to be considered with biases in their favor rather than the reverse." These three circumstances are all calamities of one kind or another. I was surprised that he did not list a fourth circumstance, that expert opinion might converge on the need for fundamental reform and on the direction which that reform should take. I believe such a development would have a shocking effect on practical men. Perhaps Bronfenbrenner considered it too unlikely to deserve mention.

Now you may ask of what use is an amateur Commission that endorses the expert consensus. If the Commission has no choice but to endorse the experts I would think the Commission serves no purpose. But Commissions do not always endorse the expert opinion and this Commission certainly did not have to. If the Commission chooses to agree with the experts, its usefulness depends upon the validity of the expert opinion. The Commission adds to the general acceptance of the expert opinion and increases the likelihood of its being reflected in policy. If the expert opinion is wrong, that is harmful. But if a Commission is going to be wrong, there is not much more harm in endorsing expert errors than in inventing its own.

A word of explanation of the Commission's background may be helpful. The Commission was not established in the belief that there was necessarily something basically wrong with the American monetary system that called for radical reform. However, the Commission was set up against the background of a great deal of criticism of the American monetary system and monetary policy, most of which focussed on the two ideas that, on the one hand, monetary policy was ineffective and, on the other hand, that it was severely discriminatory in its impact. When the Commission was established, it was stated that one of its functions would be to examine these criticisms. It was also stated that if the Commission should find no need for fundamental changes, this would also be a contribution. Therefore, from the standpoint of the expectations held when the Commission was established, its failure to recommend far-reaching changes need not be disappointing.

With respect to Harry Johnson's paper, the most serious thing $I$ have to say is Amen. I would say Amen particularly to his discussion of exchange rates and of growth as an objective of policy.

I must confess that after reading Johnson's paper I am still confused about the status of high employment and price stability as goals of national policy. I can introduce my difficulty by going back to the reason for not accepting growth as an objective. There is a prior objective, which is that people should be free to use their resources as they wish. To the extent that people, given the real opportunities that exist, want to use their resources to increase their future incomes they should be free to do so. And to the extent that they do not want to use their resources in that way they should not be required to do so. Some rate of national growth - which may be zero or negative - will emerge from these individual decisions. It seems to me this is the 
proper rate of growth. At least I do not know any other rate of growth that is better.

Much the same position can be taken about high employment. I do not know what is a good level of total employment in the country, or even a good rate of measured unemployment. We want people to be able to work if they want to do so, given the real possible conditions. Essentially this means that we want people to be able to find jobs if they are willing to work for a real wage equal to the real value of their marginal product. It seems to me, or sometimes it seems to me, that monetary policy serves its function with respect to employment if it does not frustrate the effort of workers to find work by reducing their money wages. One way to do this is to maintain and assure a stable level of prices. This is not the only way to accomplish this. Any certain rate of change of the price level would do. But if we are going to choose among certain rates of change in the price level there seem to me to be some advantages to choosing zero. We still have a large number of institutions and ways of behavior that are predicated on the assumption of zero. In any case, it does not seem to me to be the proper function of monetary policy to fool people into working for less wages than they expected. If I were forced to defend this position, I suppose I would rely on some moral precept about telling the truth.

I would like to say a word about Abba Lerner's remarks on the trade off between unemployment and price stability. I think those who are uncertain about which to choose would not be satisfied to regard the choice as between I per cent more unemployment in this year and I per cent more inflation in the same year, or even between $\mathrm{X}$ per cent more unemployment and $\mathrm{Y}$ per cent more inflation. They would insist on looking at a longer period. They would ask whether, if we accept I per cent more unemployment in this year or in the next two or three years in order to avoid inflation now, we may help to create conditions which will permit us to have both high employment and price stability over a longer period. There is at least the possibility that by placing great weight on the price stability goal now we may so affect the process of price and wage deter- mination as to resolve the high employmentprice stability conflict in the future.

Some consideration must also be given to the fact that the same noncompetitive market forces that create a conflict between high employment and price stability may also cause serious losses of efficiency through their effects on the allocation of resources. There is a danger that if we paper over the effects of these market imperfections on employment by inflation, we will accept as permanent their consequences for the allocation of resources.

I think that Johnson and I are both left with a rather small number of policy goals. I was surprised by Arthur Smithies' review of the Commission report in which he maintained that the Commission suffered from having more goals than policy instruments. I have always felt my own difficulty, in writing about these matters, to be the reverse. Perhaps because I want so little, I have found myself with more instruments than I have known what to do with. Therefore I have found myself having recourse to trivial objectives - such as minimizing the interest burden of the debt. I am still rather uncertain whether I have any objective to tell me what the size of the government surplus or deficit should be.

I believe that in a sense Johnson, through no fault of his own, has been misled in his interpretation of the Commission Report. $\mathrm{He}$ seems to believe that the goals stated by the Commission in Chapter 2 of the Report are important to the Commission's following arguments and recommendations. But it is quite clear from Johnson's own remarks, as well as from an inspection of the Report, that the goals as stated in Chapter 2 could not lead to any specific recommendations of policy except in a very loose and general way.

As I see it, the Commission did not proceed from the goals it stated to the elaboration of a specific set of policies designated to achieve them. The rationale of the Commission's recommendations seems to be something like this: There is some behavior of total money expenditures that is better than others, although the Commission does not specify what the superior behavior is. There are a number of instruments available to the government for effecting the behavior of total money expendi- 
tures. The Commission's concern is with sharpening and strengthening these instruments and getting them into the hands of wise and responsible people who will determine in what conditions and for what purposes the instruments should be used. The Commission Report does not address itself to what should be done in any particular set of circumstances. Therefore, it did not have to specify its goals more precisely than it did or resolve possible conflicts among them.

Many economists, including me, find this approach unsatisfying. What seems to me to be involved here is the old issue about rules versus authorities. A precise statement of a goal would have constituted a rule by which the authorities should be guided, even though this rule may be less operational than some other rules that have been proposed. I am not inclined to defend the unwillingness to specify rules, but since I have encountered it in many other connections I would like to offer an explanation for it. It seems to me that "practical men" and many economists have a basic difference in their approach to policy problems. The economists want to save the world and run the world from the outside. That is, they want to affect policy by writing about it rather than practicing it. Their instrument, therefore, is to lay down rules by which those who do practice policy should be governed. The practical men, on the other hand, whether of business, labor, or government, are engaged in running the world from the inside. They are making decisions; they have great confidence in their ability to make decisions and do not like to have their discretion limited by rules specified from the outside. Even businessmen who have no expectation that they will ever be in the decision-making position in the Federal Reserve or the Treasury find the point of view of the practicing monetary authorities congenial. The difference between the practical man and the economist is immediately the result of experience but may ultimately reflect some personality difference which leads each of them to choose the experience he has.

There is one obvious exception to what $I$ have just said. The pratical men have a strong affection for one particular rule, which is the rule that an ounce of gold equals $\$ 35$. I would explain this largely on the basis that the rule is a pretty old one and it is much easier to stick to an old rule than to formulate a new one. I might also point out that, far from finding the exchange rate rule a limitation on their ability to follow the domestic policy they regard appropriate, many practical men regard the exchange rate rule as a reinforcement in their effort to achieve domestic policy - especially anti-inflationary policy - that they would prefer even if there were no international financial constraints.

That leaves me with one final question. Why do many economists not like rules? It seems to me there are two possible explanations. One would be that these economists are modest about their ability to prescribe rules that would yield the desired results. I think that by all the evidence we can say that this possibility is extremely unlikely. . The other explanation is that many economists, especially many leaders of economic thinking, hold in their briefcases the baton of the chairman of a President's Council of Economic Advisers. They would not like their future freedom of action to be inhibited by rules they might lay down while in academic status.

\section{JOSEPH CONARD,}

Swarthmore College

Harry Johnson and Martin Bronfenbrenner have provided useful criticisms of the report of the Commission on Money and Credit. Since their comments are almost exclusively devoted to shortcomings of the report, an overall evaluation of the work of the Commission requires also the more favorable elements included in the remarks of the commentators. These remarks were largely devoted to Bronfenbrenner's paper, and I shall, therefore, confine my comments to Johnson's statement. With most of his fundamental analysis I am in warm agreement, and I hope this fact may not be lost sight of because of my concentration here upon points where it seems to me the momentum of his attack led him to unjustified objections and failure to give credit where credit is due.

I. I heartily support Johnson's emphasis on the conflicts between economic goals and the 
need to find some way to evaluate the net social cost or gain of sacrificing some of one goal to achieve more of another. While I do, therefore, share his regret that these conflicts among goals did not receive the emphasis they may have deserved, I think it is inaccurate to imply that they were not taken seriously in the final report of the Commission. In the chapter on which Johnson was commenting they are given explicit attention on pages $10,12,13,17$, and 39 . In relation to the relevance of these conflicts of goals it is not fair to say that the Commission simply "relies on the pious hope for other measures" than those of money and credit. What the Commission tried to emphasize is that we cannot expect monetary and fiscal policies alone to resolve these conflicts, and that other measures are, therefore, extremely important. It would hardly be appropriate for a commission on money and credit to attempt conclusions, beyond their domain, on the many wide-ranging varieties of policies that might be examined. Any other decision would surely have brought legitimate criticism from the opposite direction (see page 6 of the Commission report).

2. In evaluating the social costs of unemployment and of inflation I again find myself supporting Johnson's criticism of the Commission's tendency to give the goal of price stability a higher priority than it deserves. Yet once again I believe he failed to do the Commission justice. He says, "the report begins by conjuring up the horrors of hyperinflation," implying that the report tries to support its antiinflation position by reference to the evils of hyperinflation. My own reading. of the disputed passage (page $\mathrm{I}_{3}$ ) suggests that its intention is precisely the opposite. It states that the fear of inflation is widespread in this country, and that this fear arises from evil consequences often cited as resulting from it. The wording of the passage clearly avoids identification of the Commission with these views, and points out that these evil consequences cannot be assumed to follow from mild price increases, but have developed from hyperinflations of the kind we have no serious reason to fear in this country. Thus the entire point of the passage seems to be to allay the excessive fears of moderately rising prices.
Johnson states further that on this foundation the Commission has made the avoidance of even mild price increases a major economic goal. That is not accurate. The Commission states explicitly that it is "unreasonable" price increases which should be avoided, and never takes the position that the line should be held rigidly against any rise in the general price level. The vagueness of the term "unreasonable" may open the Commission to criticism for failing to spell out more precise guide lines, but it does not permit the charge of having stood for complete rigidity in the price level.

3. Johnson next asserts that the Commission ignores the large body of empirical evidence that arbitrary redistribution of income is difficult to detect in mild inflations. At this point Johnson's own empirical statement is only partly accurate. Empirical evidence supports the view that even mild inflation, if persistent, does alter distribution. To be sure, the alteration is not systematically away from labor or toward greater inequality as was once supposed. But significant redistribution may be seen if social groups are differently classified. Important victims are the aged and the renters of homes. Furthermore, redistribution among individuals can be undesirable even if such redistribution cancels out when these individuals are grouped.

4. Data compiled for the Commission indicated no correlation between growth rates and rates of price increase between zero and 6 per cent per year. Johnson is quite right in pointing out that these data infer compatibility of moderate price increases and growth, an inference which the Commission failed to draw. But he is wrong in denying the inference the Commission did draw, namely, that inflation is not needed as a stimulant of growth.

5. I agree with Johnson that the widely assumed negative correlation between level of unemployment and rate of growth has not been demonstrated. It is quite true that good arguments to support such a relation can be given, but contrary influences can also be cited, and empirical evidence of various kinds fails to give support for any systematic influence of the level of unemployment on the rate of growth. I also agree that in a country like the United States the case for desiring more economic 
growth than would come without our seeking it by conscious policy is chiefly a political argument related to international competition. Finally, I accept Johnson's view that monetary and credit policy can at best have only limited influence on the rate of growth.

Despite these facts I cannot see a significant objection to the Commission's selection of its three primary goals, nor do I think it legitimate to characterize them entirely as "fads." It does not seem reasonable to hold that the desire for low levels of unemployment is a fad just because it received inadequate attention before the thirties. Economic growth was an assumed goal for Adam Smith, Ricardo, Marx, and many economists since that time, though largely overlooked by the neoclassical writers. It is critically important for underdeveloped areas, and thus it acquires some importance for us in relation to aid policies. While the desire for extreme rigidity of price levels represents a current emphasis, worry over the general problem of inflation is as old as the quantity theory of money, which long antedates even classical economic writing.

To a large extent I am sympathetic with Johnson's remark that from the standpoint of economic objectives we might well accept whatever rate of growth results from individual choice between consumption and saving. However, such a statement oversimplifies the problem. So long as monetary and fiscal policies are carried out to maintain a desired level of aggregate demand, and so long as different monetary and fiscal policies have different effects on growth, some kind of growth policy is required.

These comments stress the points where Johnson seems to me to overstate his objections to the Commission report. As a result of overstatements like these, together with an almost total absence of recognition of the report's achievements, the paper gives a general impression which is seriously unfair to the achievements of the Commission. At the same time I would emphasize again my agreement with the main thrust of Johnson's more important criticisms. The purpose of this note is in no sense to give an unqualified defense of the report, but to urge a balanced evaluation.
CARL F. Christ, The Johns Hopkins University

I propose the following resolution, which clearly will command the unanimous assent of those who have spoken here:

Whereas, the United States has continued to experience some undesirable cyclical fluctuations in economic activity in recent years, and

Whereas, Mr. Herbert Stein has opined in his remarks before this conference that the number of economic goals of first importance for the United States economy is rather small compared with the number of instruments available, so that there are more instruments than one knows what to do with, and

Whereas, Mr. Milton Friedman has argued from the floor of these sessions that although in principle it might be possible for substantial fluctuations in economic activity to occur while the quantity of money was held stable, or was increased at a constant rate, in fact this has never happened, and we must respect the empirical evidence in such a case, and

Whereas, Mr. Friedman and Mrs. Anna Schwartz have argued in their paper before this conference that "sizable changes in the rate of change of the money stock are a necessary and sufficient condition for sizable changes in the rate of change of money income," and that "for minor movements . . . while the evidence was far less strong, it is plausible to suppose that changes in the stock of money played an important independent role," and

Whereas, Mr. Friedman has argued elsewhere that if the quantity of money is increased at a constant rate of say 4 per cent per year, then cyclical fluctuations of economic activity will be reduced more effectively than by any other available policy, and

Whereas, Messrs. James Duesenberry, Franco Modigliani, Hyman Minsky, Arthur Okun, and others have argued from the floor of this conference and elsewhere that changes in the rate of increase of the stock of money are not very important in generating cyclical fluctuations in economic activity, while other influences are very important, including government expenditures and taxation and interest rates and changes in the importance of money substitutes and nonbank financial institutions, and 
Whereas, the members of this conference are united in the quest for scientific truth and improved economic policy,

Now therefore be it resolved:

(I) That for the next eight years (about as long as two recent cycles) the monetary authorities be directed to follow a policy of increasing the stock of money (using Mr. Friedman's definition, currency plus demand deposits adjusted plus time deposits in commercial banks) at the uniform rate of 4 per cent per annum, or as near thereto as may be, and

(2) That the monetary and fiscal authorities be instructed meanwhile to apply whatever discretionary policies they deem most appropriate, involving deficits, surpluses, issuance and retirement of government debt, open-market operations, variation of reserve requirements, regulation of financial intermediaries, and the like, provided only that the aforementioned 4 per cent annum rule is not violated, and

(3) That in I 970 another conference be held to examine the results.

This resolution can be easily defended.

First, Mr. Friedman and those who share his policy views should support it, for it is surely a good policy if fluctuations in the rate of change of the money stock are the main cause of cyclical variations in economic activity.
Second, Messrs. Duesenberry, Modigliani, Minsky, Okun, and those who share their policy views should support it, since it offers discretionary power over variables that are the most important causes of fluctuations in economic activity if the money stock is not.

Third, it is almost inconceivable that a policy of adhering to the rule of increasing the money stock at 4 per cent per year coupled with discretionary policy in all other respects could lead to results inferior to those experienced in the United States to date.

Fourth, by executing this policy we are likely to obtain at least one of two additional benefits, as follows. (a) If economic fluctuations during the years 1962 to 1970 under this policy should turn out to be of approximately the same magnitude as we have been experiencing, then, although there would have been no improvement in policy, we would at least have gained a measure of scientific truth, namely: it would have been shown that Mr. Friedman's claims for the efficacy of the rate of increase of the money stock were exaggerated. (b) If economic fluctuations during 1962 to 1970 under this policy should turn out to be less severe than those we have been experiencing, we might still be confused on the scientific issue, but then we would at least have had eight years of greater stability than heretofore. 